\title{
A experiência pedagógica e interdisciplinar dos 40 anos do NEAM PUC-Rio na inclusão social de adolescentes de comunidades
}

The pedagogical and interdisciplinary experience of the 40 years of NEAM PUC-Rio, in the social inclusion of adolescents from communities.

\section{Davison da Silva Coutinho \\ davisoneam@puc-rio.br}

Mestre e Doutorando em Design pela PUC-Rio

\section{Helena Maria Guarisco \\ guarisco@puc-rio.br}

Mestre em Educação pela PUC-Rio

\section{Marina Lemette Moreira}

marinamoreira@hotmail.com

Doutora em Design pela PUC-Rio.

\section{Resumo}

Este artigo tem como objetivo refletir sobre as práticas pedagógicas comunitárias do Núcleo de Estudo e Ação Sobre o Menor (NEAM) da PUC-Rio, que busca articular experiência comunitária, base acadêmica e saberes populares. Para evidenciar o trabalho comunitário do NEAM realizou-se pesquisa documental em seus registros e entrevistas com cinco ex-alunos. Palavras-chave: educação; interdisciplinaridade; sustentabilidade; extensão comunitária.

\begin{abstract}
This article aims to reflect on the community pedagogical practices of NEAM PUC-Rio. NEAM, the Center for Study and Action on Minors at the PUC-Rio university, seeks to articulate community experience, academic base and popular knowledge. In order to highlight NEAM's community work, documentary research was carried out in its records and interviews with five former students.
\end{abstract}

Keywords: education; interdisciplinary; sustainability; community extension. 
COUTINHO, Davison da Silva; GUARISCO, Helena Maria; MOREIRA, Marina Lemette. A experiência pedagógica e interdisciplinar dos 40 anos do NEAM PUC-Rio na inclusão social de adolescentes de comunidades.

\section{$\underset{\text { DIENIDADE }}{\text { DISTA }}$}

Dignidade Re-Vista, v.8, n.13, nov 2021.

\section{Introdução}

Nós sofremos pela falta de qualificação. Jovens que seguem e se desenvolvem para a violência, gerando mais pobreza. Onde é que deveriam estar os estágios?

Dentro das comunidades, trocando, incentivando e aprendendo. Resultaria emenos violência.

Francisca Elizia Pirozi, líder comunitária da Rocinha, 1996

Segundo o IBGE (2020), o Estado do Rio de Janeiro possui 12,63\% de proporção de domicílios em favelas. A comunidade da Rocinha constitui um bairro vizinho ao bairro da Gávea e se localiza a cerca de dois quilômetros da PUC-Rio. Considerado o maior aglomerado subnormal $^{1}$ do país, com 25.742 domicílios e 69.356 moradores, a Rocinha registra um dos menores níveis de escolaridade da cidade do Rio de Janeiro. O acesso à educação superior é ainda um grande desafio para essa juventude, que se apresenta, em alta demanda, em todos os períodos letivos, para as inscrições no ingresso das atividades pedagógicas do NEAM.

A PUC-Rio desenvolveu, ao longo da sua história, diferentes ações afirmativas destinadas à inclusão e ao desenvolvimento das comunidades de baixa renda, sendo pioneira na política de bolsas sociais criadas pela Vice-Reitoria para Assuntos Comunitários (VRC), na década de 1990. Modalidade, inclusive, que se tornou inspiração e base para o Programa Universidade para Todos (PROUNI), criado pelo Governo Federal em 2004 (Cruz; Clapp, 2016).

Antes da política de bolsas, com a preocupação em abrir as portas da Universidade para os moradores da Rocinha, a então aluna do Departamento de Comunicação e a Prof ${ }^{\mathrm{a}}$. Thereza Penna Firme, do Departamento de Educação, iniciaram, em 1981, concebendo a possibilidade de um formato inovador, um núcleo voltado para a inclusão social com foco na juventude. Nascia assim o NEAM, Núcleo de Estudos e Ação sobre o Menor, com uma primeira atividade voltada para a rede pública, que se consolidou como Núcleo institucional da PUC-Rio em 1982.

\footnotetext{
${ }_{1}^{1}$ Termo utilizado pelo IBGE para designar assentamentos irregulares conhecidos como favelas, contando no mínimo com 51 habitações.
}

DIGNIDADE RE-VISTA | ISSN2525-698X| 2021 | V. VIII | N. 13 |Pacto Educativo Global: a busca por ressignificar a educação. Pastoral Universitária Anchieta PUC-RIO. 
COUTINHO, Davison da Silva; GUARISCO, Helena Maria; MOREIRA, Marina Lemette. A experiência pedagógica e interdisciplinar dos 40 anos do NEAM PUC-Rio na inclusão social de adolescentes de

comunidades.

\section{DIGNIDADE}

Dignidade Re-Vista, v.8, n.13, nov 2021.

\section{Construindo o NEAM: 1982 a 2019}

A PUC-Rio é uma Universidade Comunitária, de inspiração humanístico-cristã, comprometida em promover uma sociedade justa e desenvolvida. No âmbito da missão comunitária da Universidade, o NEAM estuda e desenvolve ações pedagógicas comunitárias para a integração social de jovens procedentes dos locais de menor renda da cidade do Rio de Janeiro. Tem como objetivo promover a formação de cidadãos com base educacional de excelência enquanto potenciais agentes de transformação da sociedade em que vivem.

Fundado como Núcleo de Estudo e Ação Sobre o Menor, em 1982, pela autora, é uma unidade complementar da PUC-Rio. É vinculado à Administração Central da Universidade, por meio da VRC, sendo uma iniciativa de solidariedade e fraternidade cristã, destacada institucionalmente.

Sua origem e missão inicial de "abrir as portas da Universidade para a comunidade", para a troca de saberes e desenvolvimento social, remete à campanha do NEAM "Gente que é gente ajuda o menor carente", de 1981, antes mesmo da sua fundação oficial, que arrecadou brinquedos para doação, juntos aos alunos da graduação, da PUC-Rio. Sua instalação física se deu em 1982, por meio do Conselho Nacional de Desenvolvimento Científico e Tecnológico (CNPQ), que contemplou o Núcleo em um edital de projetos emergentes, tendo também cedido sua servidora pública, então chefe de gabinete, para a coordenação executiva do NEAM.

Com a Fundação Padre Leonel França (FPLF), mantenedora da PUC-Rio, o NEAM firmou, em 1988, seu primeiro grande convênio com o Banco Nacional de Desenvolvimento Econômico e Social (BNDES). O convênio proporcionou que moradores da Rocinha se formassem em diferentes cursos, com foco em empreendedorismo. E também possibilitou a construção de dois prédios comunitários, sendo o primeiro voltado para a instalação do Centro Comunitário União Faz a Força, onde funciona uma creche comunitária, e o segundo, da Fundação Aurora, para a instalação de diferentes oficinas de capacitação e atividades de lazer.

Destaca-se que Francisca Elizia Pirozi (1996), importante liderança comunitária da Rocinha e parceira do NEAM nas iniciativas na comunidade, avaliou a experiência da parceria com as ações desenvolvidas pelo NEAM, da seguinte forma:

Os professores subiam [a comunidade], tinham contato direto com os professores desta casa, sempre havia troca, e dessa troca as pessoas foram se descobrindo e crescendo, buscaram fontes de renda e montaram seu próprio

DIGNIDADE RE-VISTA | ISSN2525-698X| 2021 | V. VIII | N. 13 |Pacto Educativo Global: a busca por ressignificar a educação. Pastoral Universitária Anchieta PUC-RIO. 
COUTINHO, Davison da Silva; GUARISCO, Helena Maria; MOREIRA, Marina Lemette. A experiência pedagógica e interdisciplinar dos 40 anos do NEAM PUC-Rio na inclusão social de adolescentes de comunidades.

negócio. Além de se descobrir o talento e a vontade das pessoas de estudar. O projeto as impulsionou a buscar parcerias fora da comunidade e da universidade. (Depoimento pessoal)

Como fundadores do NEAM, pode-se elencar: Prof. Isaac Kerstenetzky, do Departamento de Economia; Pe. João Augusto Anchieta Amazonas Mac Dowell SJ, Reitor da Universidade; Dr. José Pelúcio Ferreira, Presidente da Mantenedora; Pe. Laércio Dias de Moura SJ, Reitor da Universidade; e a Prof ${ }^{a}$. Maria Helena Novaes, do Departamento de Psicologia. O conceito da ação, apresentado no nome do NEAM, aliado à pesquisa, é explicitado pelo Prof. Danilo Marcondes (1996, p.5), do Departamento de Filosofia e antigo Vice-Reitor para Assuntos Acadêmicos: “O NEAM tem a preocupação de não ser apenas pesquisa, o próprio nome diz que é estudar o menor, mas também tem a ação que é fundamental. Esses dois aspectos são articulados pelo Núcleo". Prof. Bevilacqua (2011), antigo Vice-Reitor para Assuntos Acadêmicos, corrobora com a afirmação de Marcondes, quando afirma:

O NEAM não se restringe a diagnósticos e interpretações ou a resultados, muitas vezes estéril, de identificar culpas e culpados; ali se ensaiam e implementam soluções. O NEAM tem procurado seguir uma linha construtiva e ativa, e demonstrado que, onde há vontade e trabalho, há esperança.

O NEAM foi se construindo ao longo dos anos com o foco em proporcionar formação integral para jovens adolescentes de segmentos de baixa renda, apropriando-se do desafio de desenvolver sujeitos para além de uma dimensão intelectual. Considera-se que o saber fazer, compreendido como a grande demanda educacional desses jovens, constatada ao longo das experiências pedagógicas do NEAM, é de ordem eminentemente interdisciplinar, quando a meta é formar cidadãos com competências efetivas para participar dignamente de uma sociedade corretamente produtiva, com sólida base humanística e justa. Essa interdisciplinaridade deve possuir, necessariamente, aspectos essenciais de sustentabilidade e âmbito comunitário.

De 1982 a 2019, 36.526 moradores de diferentes comunidades participaram do NEAM. 4.637 jovens participaram dos cursos de extensão comunitária, 44 jovens concluíram a graduação, 4 concluíram a pós-graduação e 74 jovens foram admitidos nos quadros de pessoal administrativo da Universidade. Destaca-se a seguir, na figura 1, as principais realizações do NEAM, consideradas seus marcos históricos. 
COUTINHO, Davison da Silva; GUARISCO, Helena Maria; MOREIRA, Marina Lemette. A experiência pedagógica e interdisciplinar dos 40 anos do NEAM PUC-Rio na inclusão social de adolescentes de

comunidades.

\section{$\underset{\text { DIENVISTA }}{\operatorname{DIDADE}}$}

Dignidade Re-Vista, v.8, n.13, nov 2021.

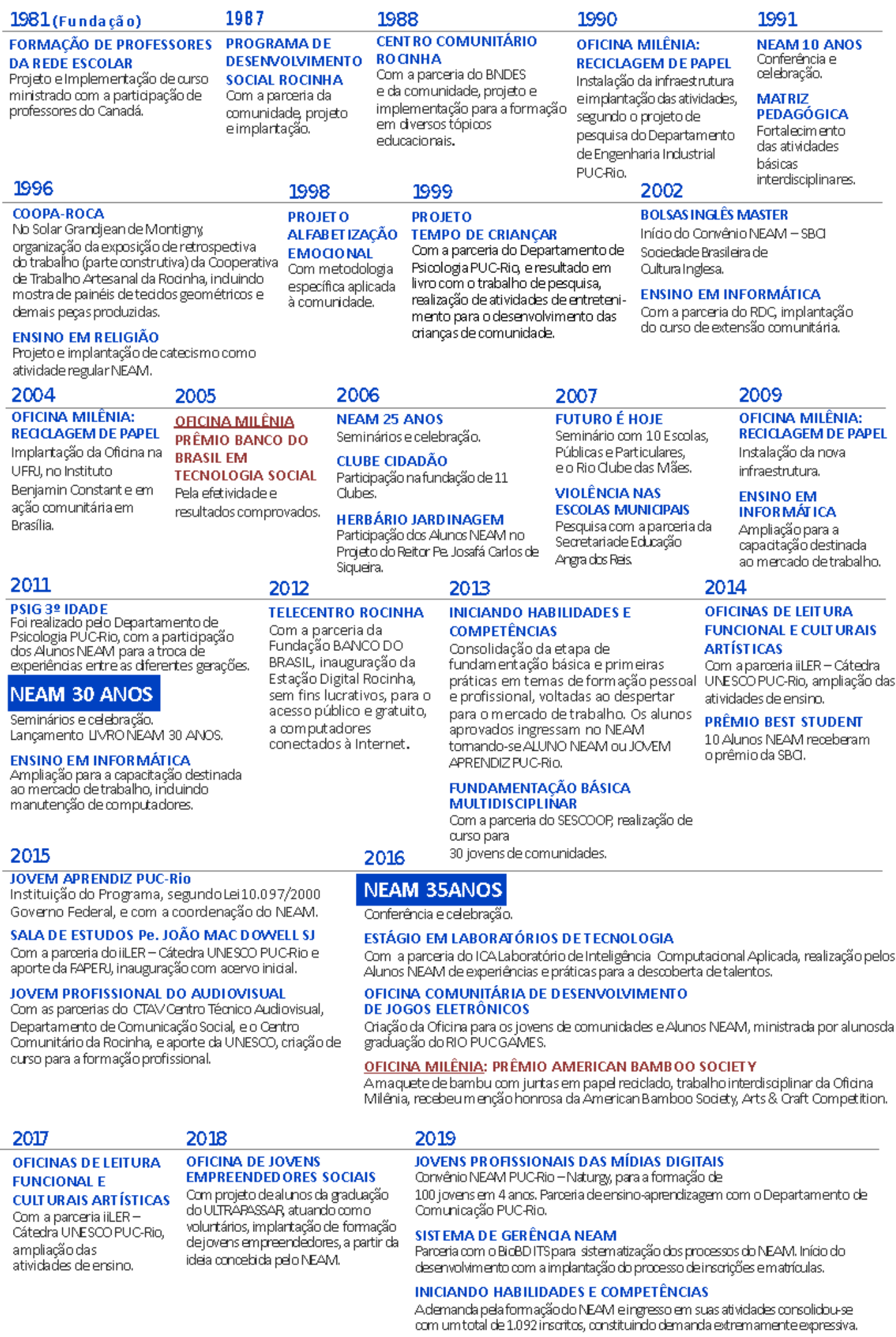

Figura 1marcos históricos NEAM 1981-2021

DIGNIDADE RE-VISTA | ISSN2525-698X| 2021 | V. VIII | N. 13 |Pacto Educativo Global: a busca por ressignificar a educação. Pastoral Universitária Anchieta PUC-RIO. 


\title{
2. O NEAM da atualidade: formação interdisciplinar, sustentável e comunitária
}

\author{
Ensinar exige estética e ética: a necessária promoção da \\ ingenuidade à criticidade não pode ou não deve ser feita à distância de \\ uma rigorosa formação ética ao lado sempre da estética. \\ Paulo Freire, 1996
}

Com foco no acolhimento e educação de jovens adolescentes de comunidades de baixa renda, o NEAM considera proporcionar formação sustentável de diferentes ordens - humana, social e ambiental. Envolvido com a educação para descobrir e desenvolver os que almejam uma vida pessoal e profissional digna, próspera e feliz, o NEAM considera como essencial que esses jovens possam praticar o saber fazer e projetar uma vida profissional promissora para o mercado de trabalho.

Entendendo a educação como um processo que deve associar o saber ao fazer, o NEAM fundamenta-se em dois movimentos: ação e reflexão, tomando a interdisciplinaridade como veículo para transportar o saber. O processo de ensino-aprendizagem efetiva-se como meio que estimula a indagação e proporciona o despertar da curiosidade, considerando-se esta como fator fundamental catalisador para a formação desses jovens. No NEAM, o aluno é o centro do processo de ensino-aprendizagem, incentivando-se que aprenda de forma participativa na resolução de desafios, refletindo e explorando soluções. O professor é o orientador-mediador da atividade pedagógica, que incentiva na determinação de caminhos e soluções adequadas. Estimula a capacidade do aluno de intervir em contexto de incertezas e complexidades. Neste sentido, configuram-se como objetivos específicos de formação desses jovens, para a vida e o trabalho:

a. Desenvolvimento de pensamento reflexivo e crítico, juntamente com a criatividade, na busca de caminhos para soluções adequadas e escolhas corretas.

b. Descobrimento de habilidades e competências próprias, que proporcionem e motivem o saber fazer bem.

c. Fortalecimento das habilidades humanas e sociais. 
COUTINHO, Davison da Silva; GUARISCO, Helena Maria; MOREIRA, Marina Lemette. A experiência pedagógica e interdisciplinar dos 40 anos do NEAM PUC-Rio na inclusão social de adolescentes de comunidades.

\section{DIGNIDADE}

Dignidade Re-Vista, v.8, n.13, nov 2021.

d. Fortalecimento de valores humanos e éticos que conduzem a vida.

e. Desenvolvimento do conhecimento cultural: línguas estrangeiras, leitura funcional dos significados do mundo, teatro e música, história e geografia.

\subsection{Os domínios interdisciplinares do NEAM}

Conforme análise dos processos atuais de ensino-aprendizagem do NEAM, o Plano de Desenvolvimento NEAM (PD NEAM, 2021-2022), elaborado pela VRC em 2020, aponta os domínios interdisciplinares (figura 2):

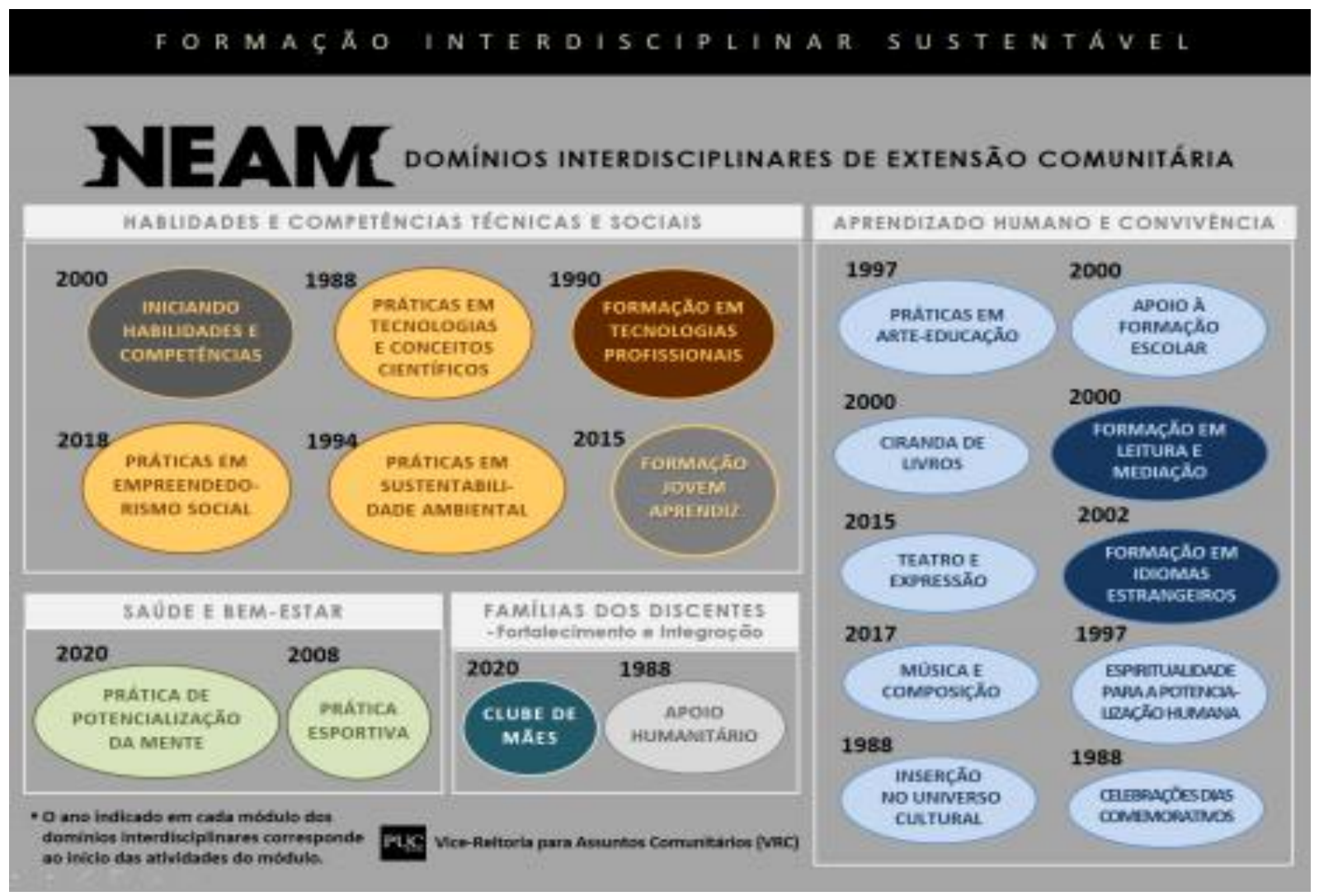

Figura 2 Plataforma NEAM: Domínios Interdisciplinares

Baseado em estudos científicos e observando o modelo da formação integral da PUCRio, o NEAM concebe esses quatro domínios interdisciplinares de extensão comunitária, que agregam módulos de iniciativas distintas para oferecer oportunidades de formação humana, social e ambiental, incluindo saúde e bem-estar, tomando a sustentabilidade como transversalidade.

DIGNIDADE RE-VISTA | ISSN2525-698X| 2021 | V. VIII | N. 13 |Pacto Educativo Global: a busca por ressignificar a educação. Pastoral Universitária Anchieta PUC-RIO. 
COUTINHO, Davison da Silva; GUARISCO, Helena Maria; MOREIRA, Marina Lemette. A experiência pedagógica e interdisciplinar dos 40 anos do NEAM PUC-Rio na inclusão social de adolescentes de comunidades.

\section{DIGNIDADE}

Dignidade Re-Vista, v.8, n.13, nov 2021.

Segundo a coordenação pedagógica do NEAM, o núcleo tem como diferencial a metodologia da interdisciplinaridade e do fomento à autonomia de aprendizado do aluno. Neste sentido, são ministradas atividades em modalidades obrigatórias e eletivas. Existe um Ciclo Básico de ingresso, constituído por disciplinas e atividades pedagógicas obrigatórias, denominado "Iniciando Habilidades e Competências", e que se encerra com um processo de certificação e seleção para o certificado tornar-se um aluno NEAM, se assim o desejar. Atividades eletivas, escolhidas a partir dos interesses e habilidades dos alunos NEAM, são igualmente oferecidas e orientadas especialmente para os perfis dos alunos NEAM participando delas. As disciplinas e atividades pedagógicas são ministradas em parceria com diferentes departamentos da Universidade.

Na lógica da sustentabilidade social, ambiental e econômica, os objetivos do NEAM estão relacionados com a Agenda 2030 da Organização das Nações Unidas (ONU).

\subsection{A metodologia pedagógica do NEAM}

A metodologia pedagógica de atuação Interdisciplinar do NEAM utiliza-se da pesquisaação Thiollent ${ }^{2}$, acrescida do enfoque do Design Social, desenvolvida em parceria com o Departamento de Artes \& Design, do Decanato de Ciências Humanas e Teologia. O campo do Design é por natureza interdisciplinar, conforme afirma Couto, "sua natureza multifacetada exige interação, interlocução e parceria" (1997, p.7) e sua abordagem social, segundo Farbiarz e Ripper (2011), desenvolve-se por meio da partilha, da troca, permitindo ir ao encontro do outro.

A interdisciplinaridade, segundo Japiassu e Marcondes (1991), é um método de pesquisa capaz de promover a interação entre duas ou mais disciplinas. Para os autores, a interação acontece por meio da comunicação das ideias até a integração mútua de conceitos. Freire (1996) também evidencia a importância da prática interdisciplinar como possibilidade de renovação da prática de ensino, possibilitando o ensinamento por meio do diálogo e integração de diferentes conteúdos.

\footnotetext{
${ }^{2}$ Como define Thiollent (1985), a característica da pesquisa-ação é quando existe uma real ação por parte dos pesquisadores e das pessoas implicadas no processo da pesquisa.
}

DIGNIDADE RE-VISTA | ISSN2525-698X| 2021 | V. VIII | N. 13 |Pacto Educativo Global: a busca por ressignificar a educação. Pastoral Universitária Anchieta PUC-RIO. 
COUTINHO, Davison da Silva; GUARISCO, Helena Maria; MOREIRA, Marina Lemette. A experiência pedagógica e interdisciplinar dos 40 anos do NEAM PUC-Rio na inclusão social de adolescentes de

No que tange à interdisciplinaridade, o NEAM, durante as primeiras décadas de existência, realizou suas atividades de ensino-aprendizagem de forma multidisciplinar, trabalhando conteúdos em diferentes disciplinas, mas ainda sem a necessidade de interligação entre elas. Nesse período, assuntos em comum eram abordados nas diferentes atividades. Por exemplo, a sustentabilidade era abordada não como um conteúdo necessariamente interligado de forma simultânea nos espaços que inspiraram o nascer do Laboratório MilêniaEmpreendedorismo com a Oficina de Reciclagem de Papel e com o Laboratório Arte-Educação, com as Oficinas de Arte-Educação. Essa característica multidisciplinar, segundo Jantsch e Bianchetti (1995), antecede à pluridisciplinaridade que ocorre quando disciplinas afins se aproximam para desenvolver o conhecimento de forma compartilhada. Em seguida, ainda de acordo com os autores, ocorre a interdisciplinaridade, em que as ações são coletivas, estão interligadas.

Segundo Freire "ensinar não é transferir conhecimento, mas criar as possibilidades para a sua própria produção ou a sua construção" (1996, p.25). Nesta lógica pedagógica, o NEAM busca construir o conhecimento a partir dos saberes de seus participantes, permitindo que a educação se construa como um modo mútuo de troca de experiências sem a tradicional hierarquia do conhecimento.

Freire ressalta que "ensinar exige respeito aos saberes dos educandos" (1996, p.17), e destaca que esse respeito deve acontecer sobretudo em relação aos alunos oriundos de classes populares, os quais, muitas vezes, tem seus saberes e práticas ignorados pela homogeneidade midiática e cultural. O autor ensina não apenas a respeitar, mas convida os educadores a fazer uso desses saberes como metodologia de ensino. Como exercício, ele propõe utilizar a experiência dos alunos em suas comunidades de origem como objeto de estudo para as disciplinas.

A abordagem de Freire (1996) é encontrada na metodologia do NEAM ao ministrar suas diferentes atividades de formação pedagógica comunitária. Um exemplo prático acontece no Laboratório de Audiovisual: Produção em Mídias Digitais, no curso de extensão comunitária “Jovens Profissionais do Audiovisual”, em que o projeto final de curso é a produção de pequenos documentários com temas como sustentabilidade, educação, cultura, saneamento e mobilidade sobre as comunidades onde os participantes residem. 
COUTINHO, Davison da Silva; GUARISCO, Helena Maria; MOREIRA, Marina Lemette. A experiência pedagógica e interdisciplinar dos 40 anos do NEAM PUC-Rio na inclusão social de adolescentes de comunidades.

\section{$\underset{\text { DIENVISTA }}{\operatorname{DIDADE}}$}

Dignidade Re-Vista, v.8, n.13, nov 2021.

Para o NEAM, as atividades de ensino-aprendizagem devem, essencialmente, constituir, para o aluno, dimensão de valorização do ser humano e de sociabilidade, proporcionando o despertar de novas possibilidades, a percepção da beleza ou estética das coisas do mundo e de si próprio, a curiosidade no aprender para evoluir e criar, a descoberta de talentos próprios e de potencialidades.

\section{Plano de Desenvolvimento NEAM 2021-2022: Laboratórios de Ensino-}

\section{Aprendizagem, Fabricação e Mercado}

O Plano de Desenvolvimento NEAM 2021-2022, identificou a estrutura organizacional apresentada na figura 3 a seguir:

PUC-Rio Vice-Reitoria para Assuntos Comunitários

ESTRUTURA ORG ANIZACIONAL DASATIVIDADES

I R E Ç Ã O

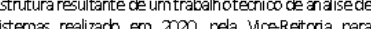
Assuntos Comunit́rios para a produç̃o do Plano de Desenvolvimento NEAM 2027 , en coniunto com a

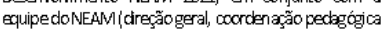
e achinistr twa-fin anogira, e intritores das atvidades de ensino aprendizagent. O trabalho tevecomo dbjefivo representar $æ$ atvicades esua insitudion alicade

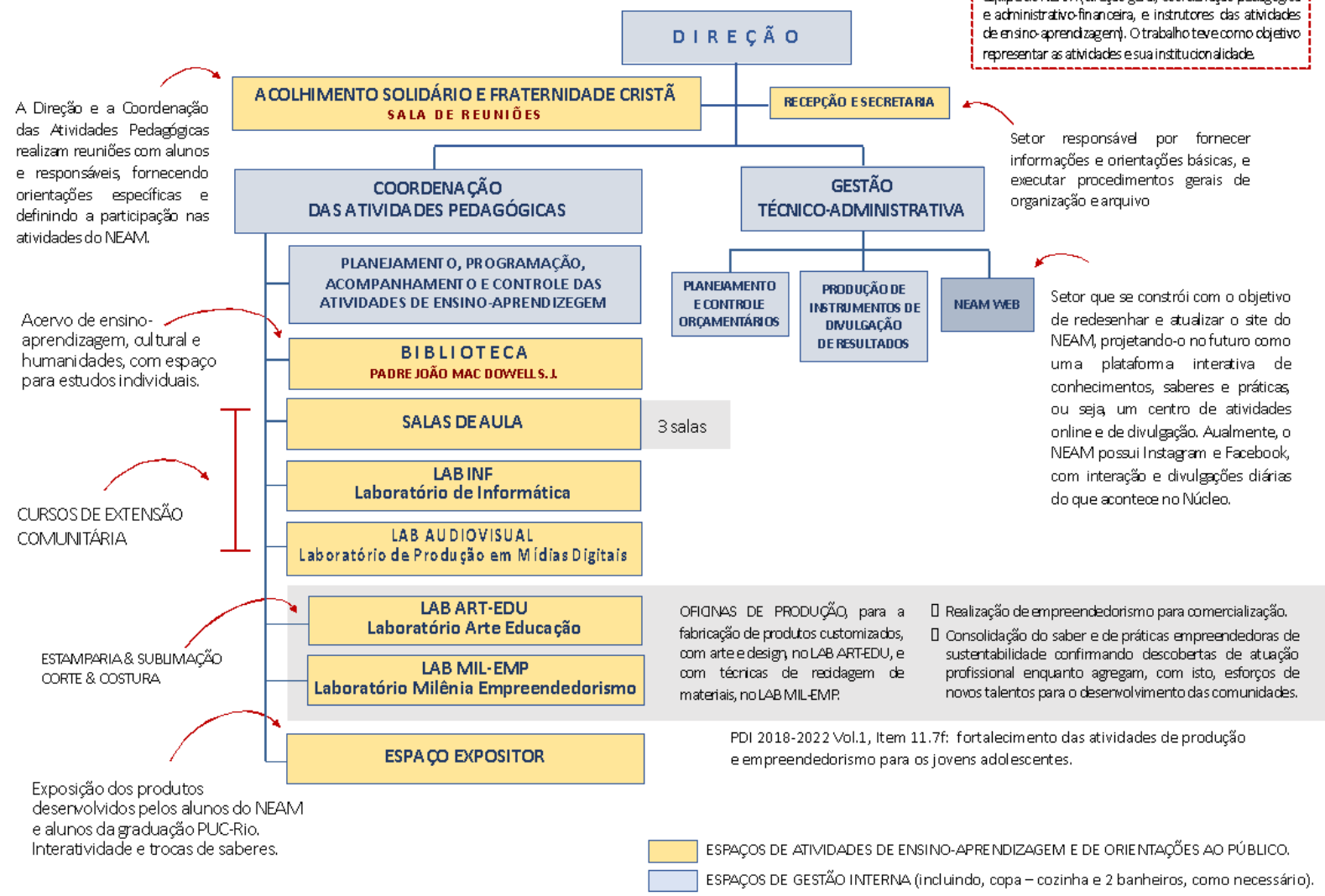

Figura 3 Estrutura organizacional

DIGNIDADE RE-VISTA | ISSN2525-698X| 2021 | V. VIII | N. 13 |Pacto Educativo Global: a busca por ressignificar a educação. Pastoral Universitária Anchieta PUC-RIO. 
COUTINHO, Davison da Silva; GUARISCO, Helena Maria; MOREIRA, Marina Lemette. A experiência pedagógica e interdisciplinar dos 40 anos do NEAM PUC-Rio na inclusão social de adolescentes de comunidades.

Nessa estrutura, destacam-se os Laboratórios de Arte-Educação (LAB ART-EDU), Milênia-Empreendedorismo (LAB MIL-EMP) e o de Produção em Mídias Digitais (LAB de Audiovisual) como centros de ensino-aprendizagem, fabricação e mercado. Esses centros visam proporcionar, por meio da metodologia pedagógica indicada no item 2.2, uma experiência concreta dos alunos com o mundo real, aprendendo e produzindo conteúdo a partir de vivências em suas comunidades, articulando-as com os conhecimentos da Universidade. Nos espaços de prática e criação desses Laboratórios, convida-se o aluno a experienciar o mundo como um labirinto, com base no que o afirma Ingold “(...) o termo a educere, ou seja, ex (fora) + ducere (levar). Nesse sentido, educar é levar os noviços para o mundo lá fora (...), significando, literalmente, convidar o aprendiz para dar uma volta lá fora” (2017, p.3). Nesses laboratórios, o despertar da curiosidade é visto como essencial para a transversalidade nas práticas de ensinoaprendizagem do NEAM.

No LAB MIL-EMP, a Oficina de Extensão Comunitária "Reciclagem de Papel: A Criatividade Colaborando com o Meio Ambiente", apresenta a importância, os conceitos e a prática da reciclagem de papel, baseada em processo semi-industrial, utilizando a Máquina Milênia. A máquina foi idealizada pelo Prof. Eugênio Leal, do Departamento de Engenharia Industrial, em 1999, com o objetivo de transportar o conhecimento do pesquisador para a formação do jovem técnico (Moreira, 2006). A conscientização sobre as necessidades para a sobrevivência e sustentabilidade do planeta é destacada, enquanto se estimula o desenvolvimento da autoconfiança e as potencialidades humanas dos alunos.

Conforme afirma Leal (1996), o uso da tecnologia apropriada à produção do papel reciclado tem duplo impacto social. De um lado, entrega nas mãos dos jovens a possibilidade de aprender na prática como solucionar problemas, reaproveitando matéria-prima e transformando-a em objeto necessário à sua demanda. Por outro lado, incorpora, ao processo produtivo, essa mão de obra, capacitando e conduzindo-a a assumir novas tarefas em setores mais modernos da economia, evidenciando o potencial para a geração de renda.

No LAB ART-EDU, parceria com o Departamento de Artes \& Design, realiza-se a Oficina "Plano Bonecos" ministrada pelo prof. Eduardo Andrade, que objetiva a experiência do despertar para o conhecimento literário e o entendimento de conceitos de arte e desenho técnico, com o aproveitamento criativo de resíduos. Os bonecos literários são produzidos por meio de processo de acoplagem de peças, no caso, de resíduos, como os obtidos por reciclagem, 
COUTINHO, Davison da Silva; GUARISCO, Helena Maria; MOREIRA, Marina Lemette. A experiência pedagógica e interdisciplinar dos 40 anos do NEAM PUC-Rio na inclusão social de adolescentes de comunidades.

\section{$\underset{\text { DIEN }}{\text { DIDADTA }}$}

Dignidade Re-Vista, v.8, n.13, nov 2021.

sendo o design baseado na transposição de ilustrações e desenhos bidimensionais em figuras ou personagens tridimensionais, utilizando processo analógico.

O LAB Audiovisual, parceria do Centro Técnico de Audiovisual (CTAv) do Departamento de Comunicação com o Programa Criança Esperança, a Unesco e a Natugy Brasil, realiza, desde 2015, o Curso de Extensão Comunitária “Jovem Profissional das Mídias Digitais". Os exercícios abordam temáticas com as realidades dos jovens alunos, trazendo o universo cultural de suas comunidades de origem. O trabalho de conclusão de curso (TCC) inclui relevâncias próprias desses espaços, como sustentabilidade, educação e mobilidade. A formação conecta-se ao mercado de trabalho em expansão, abrangendo as áreas de produção em vídeo, cinema, televisão e informática, exercício das funções de assistência de câmera, de edição digital, iluminação, áudio e operação de computadores.

$\mathrm{Na}$ perspectiva da extensão comunitária, o LAB Audiovisual envolve-alunos de diferentes áreas de graduação da PUC-Rio, em especial do Departamento de Comunicação Social e de Artes \& Design.

\section{A relevância do trabalho do NEAM}

O NEAM sempre teve o cuidado de proporcionar uma formação integral aos adolescentes, onde as dimensões educativas e profissionais estão sempre associadas à formação humanística e religiosa.

Pe. Josafá Carlos de Siqueira SJ, Reitor da PUC-Rio

Com portas abertas para os jovens adolescentes, o Neam proporciona uma oportunidade efetiva para aqueles que desejam bem formar-se para uma vida promissora, com trabalho competente, íntegro e digno. Prof. Augusto Sampaio, Vice-reitor Comunitário

Foram analisadas as entrevistas de cinco antigos alunos NEAM. As entrevistas foram realizadas por meio de roteiros informais com jovens residentes em diferentes locais e participantes do NEAM em diferentes períodos. Os conteúdos das entrevistas serão comentados a partir do referencial teórico apresentado, a metodologia e os objetivos do NEAM. A fim de 
COUTINHO, Davison da Silva; GUARISCO, Helena Maria; MOREIRA, Marina Lemette. A experiência pedagógica e interdisciplinar dos 40 anos do NEAM PUC-Rio na inclusão social de adolescentes de comunidades.

\title{
$\underset{\text { DIEN VISTA }}{\text { DIDADE }}$
}

Dignidade Re-Vista, v.8, n.13, nov 2021.

preservar a identidade dos entrevistados, os nomes verdadeiros dos foram trocados por nomes fictícios. O processo de ensino-aprendizagem do NEAM visa a formação de multiplicadores do conhecimento e, primordialmente também, da aplicação do conhecimento ao reconhecimento de problemas locais. De acordo com o evidenciado por Freire (1996) e baseado na metodologia de atuação do Núcleo, Haoni Gouveia, aluno NEAM entre os anos de 1988-1992, relata sua experiência:

\begin{abstract}
Depois da família NEAM ter me acolhido, eu saí dessa região pequena em São Gonçalo para viver outras realidades, sobretudo sobre o impacto ambiental e social. Ao me formar em geografia e direito pela PUC eu tive um suporte do NEAM que foi fundamental com os cursos de inglês e de informática. Isso foi essencial para que hoje eu possa voltar para minha comunidade e dar algum alento aos problemas locais. (Depoimento pessoal, Haoni Gouveia, advogado e mestre em Geografia PUC-Rio)
\end{abstract}

Haoni ressalta a importância da interdisciplinaridade nas atividades de ensinoaprendizagem oferecidas pelo NEAM. Os objetivos específicos do NEAM, para o fortalecimento de valores humanos e éticos e para o desenvolvimento do conhecimento cultural, são igualmente evidenciados em sua entrevista.

Monalisa Lisboa, aluna NEAM entre 2001 e 2006, expressa o quanto o NEAM proporciona a integração, na sociedade, de jovens procedentes de espaços de mais baixa renda:

Adquiri, com a ajuda do NEAM, muitos certificados, diplomas, e consequentemente muitas oportunidades que sei que são raras, principalmente para pessoas oriundas de comunidades. Dou aula de português em uma cidade no Estado de Nova Iorque, que teria sido impossível conseguir sem a minha história com o NEAM. Por isso, e muito mais, posso dizer que o NEAM mudou minha vida, me fez acreditar em mim, me abriu as portas para o mundo. (Depoimento pessoal, Monalisa Lisboa, graduada e mestre em Letras PUC-Rio)

A afirmação de Monalisa, sobre o sentimento de mudança de vida e o acolhimento do NEAM, também é abordado pela jovem Tatiana Souza, participante do NEAM entre 2010 e 2013:

Eu conheci o NEAM em 2010, assim que tive a perda da minha mãe pela violência. Eu era uma adolescente sem expectativa, sem sonhos e com o mundo destruído quando o NEAM entrou na minha vida. E eles me fizeram

DIGNIDADE RE-VISTA | ISSN2525-698X| 2021 | V. VIII | N. 13 |Pacto Educativo Global: a busca por ressignificar a educação. Pastoral Universitária Anchieta PUC-RIO. 
COUTINHO, Davison da Silva; GUARISCO, Helena Maria; MOREIRA, Marina Lemette. A experiência pedagógica e interdisciplinar dos 40 anos do NEAM PUC-Rio na inclusão social de adolescentes de comunidades.

sonhar e acreditar que era possível ainda ter um futuro. (Depoimento pessoal, Tatiana Souza, graduada em administração na PUC-Rio)

Arthur Lins, aluno NEAM entre os anos 2010 e 2014, e hoje professor de Jiu-jítsu em escola nos Emirados Árabes Unidos, traduz a importância do processo vivenciado no NEAM para a construção dos objetivos de vida:

O NEAM foi fundamental na minha vida e tem uma lição que eu carrego até hoje: quando a gente começa alguma coisa, a gente sempre quer chegar logo no final. Só que às vezes o caminho que a gente traça é mais importante que o próprio resultado. Esse caminho nos dá vivência e principalmente experiência e maturidade. (Depoimento pessoal, Arthur Lins, aluno)

O depoimento e a trajetória de Arthur confirmam os objetivos principais do NEAM referentes ao desenvolvimento do pensamento reflexivo e crítico, ao descobrimento de habilidades e competências próprias, e o fortalecimento das habilidades humanas e sociais. Elementos igualmente presentes na entrevista de José Vechi, aluno NEAM entre 1998 e 1999:

O NEAM foi muito importante para mim porque lá eu cresci, quando as pessoas na minha família, escola e trabalho nem sempre se importavam comigo. O NEAM me acolheu, não só abriu as portas da universidade, mas me ajudou no momento mais difícil da minha vida. Tenho muita gratidão à professora. (Depoimento pessoal, Graduado em administração na PUC-Rio e com MBA no Texas, EUA)

Karina Silva, participante do NEAM entre 2012 e 2019, ressalta as oportunidades e a formação cidadã, oferecida pelo NEAM, em sua trajetória de vida:

O NEAM abriu muitas portas na minha vida, fazendo-me crescer profissionalmente e academicamente. Tornei-me graduanda em Administração e certamente, é o primeiro degrau de uma longa escada para o sucesso. Acredito que essa experiência e vivência, iniciada, na verdade, quando eu ainda era pré-adolescente, estejam contribuindo de forma fundamental em minha entrada na vida adulta, no meu comportamento como profissional, nos meus valores como ser humano e nas minhas esperanças como cidadã brasileira. (Depoimento pessoal, Karina Silva, aluna de administração PUC-Rio)

Os resultados das entrevistas apontam a extrema relevância do trabalho de formação interdisciplinar, sustentável e comunitário, implantado pelo NEAM. Em 2020, o Núcleo 
COUTINHO, Davison da Silva; GUARISCO, Helena Maria; MOREIRA, Marina Lemette. A experiência pedagógica e interdisciplinar dos 40 anos do NEAM PUC-Rio na inclusão social de adolescentes de comunidades.

\section{$\underset{\text { DIGEVISTA }}{\text { DIDADE }}$}

Dignidade Re-Vista, v.8, n.13, nov 2021.

recebeu uma demanda de inscrições para o ingresso no seu ciclo básico de 1.000 candidatos, com um total de 334 matriculados $(23 \%)$ e, posteriormente, 273 alunos formados (82\%). A demanda crescente aponta a extrema relevância do trabalho de formação interdisciplinar, sustentável e comunitário, concebido e implantado pelo NEAM. Pretende-se que as questões apresentadas possam ajudar a compreender o significado das ações do NEAM na vida de jovens de espaços de baixa renda, contribuindo também para a comunidade científica e demais projetos e iniciativas do Terceiro Setor ${ }^{3}$.

\section{Conclusão}

O NEAM sente-se extremamente honrado com o apoio dado pela Reitoria da PUC-Rio e pela VRC. A contribuição acadêmica de professores parceiros e alunos da graduação e pósgraduação da PUC-Rio e o reconhecimento de seus antigos alunos é igualmente motivo de especiais agradecimentos.

Para este artigo, foi realizada uma pesquisa documental, incluindo a de caráter histórico, de registros do NEAM ao longo de 40 anos, contemplando a sua evolução através de décadas de existência. A proposta foi evidenciar como o NEAM se construiu e está consolidado atualmente, sempre determinantemente focado em proporcionar a esses jovens condições de formação humana, social e profissional, essenciais para as suas vidas, motivando-os a descobrir seus talentos e potencialidades para melhor viverem. Para dimensionar como o NEAM se projeta atualmente, para atender a essa demanda, foi assinalada a estrutura organizacional correspondente, totalmente voltada para o acolher e educar, destacando-se os três laboratórios de ensino-aprendizagem, fabricação e mercado como grandes propulsores do formar.

\footnotetext{
${ }^{3}$ Termo utilizado para definir organizações de iniciativa privada, sem fins lucrativos e que prestam serviços de caráter público.
}

DIGNIDADE RE-VISTA | ISSN2525-698X| 2021 | V. VIII | N. 13 |Pacto Educativo Global: a busca por ressignificar a educação. Pastoral Universitária Anchieta PUC-RIO. 
COUTINHO, Davison da Silva; GUARISCO, Helena Maria; MOREIRA, Marina Lemette. A experiência pedagógica e interdisciplinar dos 40 anos do NEAM PUC-Rio na inclusão social de adolescentes de comunidades.

\section{Referências bibliográficas}

BALANÇO SOCIAL NEAM VRC PUC-Rio, 2019 e 2020. Vice-Reitoria para Assuntos Comunitários, 2020.

BEVILACQUA, Luiz. Livro NEAM PUC-Rio 30 anos. Vice-Reitoria para Assuntos Comunitários PUC-Rio, Rio de Janeiro, 2011.

CENSO Domiciliar na Rocinha. Secretaria de Estado da Casa Civil do Rio de Janeiro. 2011. Disponível em http://g1.globo.com/rio-de-janeiro/noticia/2011/12/maior-favela-do-paisrocinha-discorda-de-dados-de-populacao-do-ibge.html Acesso em: 12 set 2021.

COUTO, R. M. S. Movimento interdisciplinar de designers brasileiros em busca de educação avançada. Tese de Doutorado. Departamento de Educação PUC-Rio, 1997.

CRUZ, Lais, Adelita de Souza e CLAPP, Andréia. Ação Afirmativa no Ensino Superior - Um Estudo sobre o Programa Universidade para Todos (PROUNI). Departamento de Serviço Social PUC-Rio, 2016.

INGOLD, Tim. O dédalo e o labirinto: caminhar, imaginar e educar a atenção. Horizontes Antropológicos, Porto Alegre, 2017.

IBGE - INSTITUTO BRASILEIRO DE GEOGRAFIA E ESTATÍSTICA. Levantamento Aglomerados Subnormais: Classificação preliminar e informações de saúde para o enfrentamento à Covid-19. Rio de Janeiro: IBGE, 2020. Disponível em:< https://biblioteca.ibge.gov.br/visualizacao/livros/liv101717_notas_tecnicas.pdf>. Acesso em: 4 nov 2021.

FARBIARZ, J.; RIPPER, L. In: COELHO. Luiz; WESTIN. Denise. Estudo e Prática de Metodologia em design nos cursos de pós-graduação. Rio de Janeiro: Novas Ideias, 2011. 
COUTINHO, Davison da Silva; GUARISCO, Helena Maria; MOREIRA, Marina Lemette. A experiência pedagógica e interdisciplinar dos 40 anos do NEAM PUC-Rio na inclusão social de adolescentes de comunidades.

\section{$\underset{\text { DIGNIDADE }}{\text { DISTA }}$} Dignidade Re-Vista, v.8, n.13, nov 2021.

FREIRE, P. Pedagogia da autonomia: saberes necessários à prática educativa. São Paulo: Paz e Terra, 1996.

JANTSCH, Ari; P. BIANCHETTI, Lucídio. Interdisciplinaridade: para além da filosofia do sujeito. Petrópolis: Vozes, 1995.

JAPIASSU, H.; MARCONDES.D. Dicionário básico de filosofia. Rio de Janeiro: Zahar, 1991.

LEAL, José Eugênio. Publicação especial 15 anos do NEAM PUC-Rio. Rio de Janeiro,1996.

MARCONDES, Danilo. Publicação especial 15 anos do NEAM PUC-Rio. PUC-Rio, Rio de Janeiro, 1996.

MOREIRA, M. Universidade e Comunidade: a construção de um novo ambiente. Rio de Janeiro: E-paper, 2006.

MOREIRA, Marina; BASTOS F ${ }^{\mathbf{o}}$, Audir; COUTINHO, Daviso. (orgs.). NEAM 30 Anos. PUCRio - Vice-Reitoria Comunitária, Rio de Janeiro, 2011.

PLATAFORMA AGENDA 2030. ONU. Disponível em 〈http://www.agenda2030.com.br/>. Acesso em: 6 nov 2021.

PLANO de Desenvolvimento Institucional PDI PUC-Rio 2018-2022, item 11.7 "Extensão e responsabilidade social. Coordenação Central de Planejamento e Avaliação, 2018.

PLANO de Desenvolvimento PD NEAM PUC-Rio 2021-2022. Vice-Reitoria para Assuntos Comunitários, 2020.

Pirozi, Elizia. Publicação especial 15 anos do NEAM PUC-Rio. NEAM PUC-Rio. Rio de Janeiro, 1996.

DIGNIDADE RE-VISTA | ISSN2525-698X| 2021 | V. VIII | N. 13 |Pacto Educativo Global: a busca por ressignificar a educação. Pastoral Universitária Anchieta PUC-RIO. 